\title{
Rethinking of Design Color Teaching
}

\author{
Zhenglei Dong \\ Huanghe Science and Technology College \\ Zhengzhou, China
}

\begin{abstract}
Design color is a required professional course of design. In comparison with basic color courses of other majors, the teaching effect of this course directly influences students' learning of other successive specialized courses. During the course of teaching, only improving teaching methods according to the characteristics of visual communication design can we play the role of design color teaching. This paper conducts research and exploration on design color course teaching, that is to cultivate students' ability of discovering and creating beauty in the nature based on color sketching and train their subjective color consciousness and creativity mainly in color training induction; focus on feeling expression of color psychology and color emotion and cultivate their expression ability of subjective color; arouse students' learning interest and improve their flexible application ability of color design through synaesthesia expression of color. In addition, we should reform the contents of design color specialized course in universities and colleges and cultivate students' ability of effectively applying design languages in design practice.
\end{abstract}

Keywords—design color; teaching method; content

\section{INTRODUCTION}

Color, as the basic morpheme of design art, is a required art skill of artist to master and apply no mater in art of painting, design or modern multimedia art field. Accurate application and proper grasp of color can build various artistic conceptions; in addition, color has functional effects of language communication, visual identity and interactive experience in design field.

\section{CURRENT SitUATION AND EXISTED PROBLEMS OF DESIGN COLOR TEACHING}

\section{A. The courses of design color}

Design color, carrying on the color teaching mode of fine arts in institutions of higher education as before, is a new subject curriculum arising from intermingling fine art and design art, which requires, distinguishing from the color sciences of painting major in fine art colleges, high generalization, extraction, refinement and conclusion on the base of fine art; meanwhile, it expresses imaginative color with decorative design feeling flexibly, dramatically and ideally. With regard to the color courses of fine arts in institutions of higher education, it conducts teaching by means of facsimile and painting from life, specially emphasizing on cultivating students' ability of drawing objects and expressing light and color, so as to make students acquire the color basic knowledge required by the major and in teaching design color course, it also uses the same method. However, due to thin painting basis of students and limited class hours of both courses, students can hardly connect the limited color knowledge with their own majors, which will result in that learning design color plays little function on their later specialized courses.

\section{B. Definition of "Design Color" Less than Accurate}

At present, many color courses of design major take name are entitled "design color", however, they lack of deeply research on what is "design color" in the adoption of teaching contents and methods. In respect to training students, it is only limited to the combination teaching of sketching and facsimile, which purses to verisimilar painting effect, but it does not deeply combine with the design principle or effectively embody "design".

\section{Confliction between Teaching Materials Selection and Course}

Concerning selection of teaching materials, proper specialized materials are required combining with the requirements and characteristics of talents specialized in design. However, in practical teaching, fewer schools select teaching materials planned by the Ministry of Education indeed while more universities select gouache teaching materials which may misunderstand students' cognition to this subject, resulting in that they will consider design color course as painting, even after class, what they have learned is only limited to painting. Students may lack of observation, summarization, induction and creation consciousness of color, they will still only focus on depicting objects and their abilities of color design and aesthetic creation are not well trained or improved.

\section{Large Differences among Students on Color Basis}

Most students in design major are non-art students of arts and sciences and part-time adult students; in addition to a little art fine learning in middle and primary school of students, they have zero painting foundation, lack of painting expression of color and artistic culture as well as worse artistic sense, which needs to practice starting from the most basic single still life. However, individual students possess better foundation of fine art, among which, some have participated in the entrance examination of fine art, even passed the examination of provincial joint examination or the eights fine art colleges of China and they possesses solid painting foundation. Due to large difference among students, gouache painting training is not good for teachers conduct cultivation in differences, and 
even if the teachers adopt education in differences with consciousness, it may cause superiority of students, even lose their study.

\section{CONSTRUCTION OF DESIGN COLOR COURSE AND EXPLORATION OF TEACHING REFORM}

\section{A. Teaching Significance of Design Color}

Design color courses train and cultivate students' modeling ability, visual language, aesthetic consciousness and creation ability of design. As a relatively important expressive factor, color usually plays a role of enriching art moulds and showing their functions, meanwhile its exaggeration of atmosphere and expression should not be ignored. For a long time, there are lots of misunderstandings existing in the teaching process of design color due to extensity of art. For instance, mainly emphasizing on "reappearance" in color and severely ignore the subjective color practice; insisting on traditional skills in the training of pure painting languages. Therefore, deformation, combination and composition principle and other similar problems not only exist in modern drawing. With regard to design color teaching, aiming at cultivating students' qualities, it requires changing the common practices and breaking through the traditional design principle of color to surpass predecessors in drawing skills and experiences; meanwhile, it emphasizes on analysis design element of visual language and make students rethink color knowledge as well as cultivate their learning method of thinking in comprehensive ways to improve their expression ability. As a basic subject, design color is to train students' ability of observing the lays of colors in nature, and the objectives of practicing their ability of acute natural color feelings is to train their understanding, grasp and application of color emotion, as well as practicing their acute color emotion feeling ability, understanding the universality of color feelings, excavating personalization of personal color, learning the application of color comparison and coordination relationship; meanwhile training their abundant color matching skills.

\section{B. Teaching Content Reform Closely Linked with Majors}

Due to thin painting basis of students in design major, the writer reform the original teaching contents for students learning basic knowledge closely linked to the major (interior design) from limited classroom. That is transforming the original "single still life - combination of single still life complex still life" to "single still life - simple still life complex still life - interior scene - architecture view", which is a process of simple to complex and basic ability training to professional ability cultivation, and it can train students abilities of summarization, induction, extraction and decoration of colors.

\section{Colors and Visual Communication}

Visual communication of color realizes the information communication function acting on people mainly through the emotion performance of color and contrast and consonance. Emotion performance of color refers to color giving rise to psychological reflection and association of thoughts through visual stimulation. And such psychological reflection and association of thoughts are psychological experiences people formed in long-term social practice. For example, the color of black makes people feel mysterious, bloodcurdling, dark and dignified; red makes people feel excited, passionate, enthusiastic and stimulated. Whether other natural animals or organisms have the same color emotion communication symbols with human, or similar color is unique performance mechanism of color emotion for some organisms, plays an important role for human's design in special field. During design color study, students can further expand their horizons and deepen their cognition of color emotion communication through research on the color emotion performance of bionic color. Within color system, through contrast and consonance of different colors, it builds its own color system and own world of color languages.

\section{Color Teaching Method and Program of Design Major}

With the purpose of cultivating students' design performance ability, color learning of design major gradually transforms simple color description to subjective design color. In conclusion, it mainly includes as follows:

1) Change the realistic color of environment or subject: In this step, it requires students firstly conducting color sketching of the subject on regular basis, then changing some subjects or interlinings of the still life to change the color of partial still life. This is mainly to cultivate students' observation ability and make them understand colors on whole meaning, such as learning how to observe and analyze colors wholly. The more important thing is to make them discover some laws and lay foundation of color application for other design class later.

2) Generalization and extraction of color: As we know, design task is implemented by virtue of materials based on certain practical purpose or propaganda purpose. Therefore, design color has its own characteristics - complanation, standardization, mechanical, intellectuality and artificiality; in addition, it subjects to the makings. Hence, it cannot be represented in form of realistic color, as well as it must correspond to requirements of design itself and realize its design task through reduction, exaggeration, sublimation, moral and even symbolization of color. In this step, we conclude, summarize and refine still life of same group on the basis of realistic color. That is rationally transforming colors within close scope to their average color. The objective of training is cultivating students' full and deep cognition of color. Technique of representative writing mainly adopts flat painting, which can transform the drawing and coloring methods of students in design major from painting view to the applied tools and methods of design characteristics as soon as possible.

3) Space color: Space color sketch training is to make students fully understand the organization and laws of colors in space and anew review the basic characteristics of color from the view of space. In the teaching of this unit, we firstly place various and complex subjects in large space environment, so as to transform some subjects from a main 
position to a subordinate position in large space or a composition of the space, then the colors of all parts of the picture change again, which requires students starting from larger color relationship, whole color and basic characteristics of color to review the space color. Secondly, it requires fully knowing and understanding the deep space and plane space. And the other teaching objective of large space color training requires students analyzing the color region, color changes and causes of large colors in space. Also it requires students resolving the duality of image space organization that is the deep space and plane space. At last, attentions should be paid on color integration. Color integration is to design and integrate natural color by means of color laws. Through analysis on possibility of color and tone of specific objects, design a new color composition, it can define the basic color of the original objects and form a new color image through changing the proportion relationship among different colors or adjust and integrate the interrelation of colors. If considering the photochromic sketch training of color and space color sketching training as passive cognition and reflection, the research on color integration can be considered as a conversion of passive moulding to subjective color design. The process of color integration is to establish color harmony relation in image, design and organize image color and construct a color relation in accordance with color laws.

4) Abstract color: Color abstraction derives from the writer conducting a kind of intuition breaking away from vision on affirmed objects and refers to the crystallized consciousness re-derived through cerebral integration. This is mainly to further cultivate students' abilities of cognition and grasp of realistic color to abstract color, and make students initially involve in the color thinking model of design thought from the evolution of color to color symbol. Abstract colors always carry a feeling of ideal and desire and clearly show nature by means of symbolism. Training of abstract color requires students understanding colors from apperceived hue, brightness, purity and saturation; in addition, it requires students deep researching the image color when they evolving image colors, so that the colors in final abstract image can have both signified characteristics and designation characteristics conveying the contents and vision of image. When human researching the color world of organism, it shall deeply interpret and research the color matching skills, matching information semantic as well as the color matching differences of different species.

\section{CONCLUSION}

In the process of teaching, only improving teaching method according to the characteristics of visual communication design can we play an excellent role in design color teaching process. This paper conducts research and exploration on design color course teaching, that is to cultivate students' ability of discovering and creating beauty in the nature based on color sketching and train their subjective color consciousness and creativity mainly in color training induction; focus on feeling expression of color psychology and color emotion and cultivate their expression ability of subjective color; arouse students' learning interest and improve their flexible application ability of color design through synaesthesia expression of color.

\section{REFERENCES}

[1] Xue Guiyi. Reflections on Reform of Design Color Teaching. Art Education Research. 2013;

[2] Li Xiaoguang. Preliminary Exploration of Higher Vocational Education System. Education and Career. 2009;

[3] Huang Xiao. Exploration of Design Color Teaching Reform in Higher Vocational College. China Science and Technology Review, 2014;

[4] Yuan Gongren. Design Color and Innovative Thinking. Art Education, 2006 